\title{
Three flavonoids from Cycas revoluta
}

\author{
Ying $\mathrm{Xu}^{\mathrm{a}, *}$, Qichang Dai ${ }^{\mathrm{a}}$, Zongze Luan ${ }^{\mathrm{a}}$, Zheng Xiang ${ }^{\mathrm{a}}$, Jian $\mathrm{Wu}^{\mathrm{a}}$, Yuling Fan ${ }^{\mathrm{a}}$ \\ ${ }^{a}$ Research Center on Life Sciences and Environmental Sciences, Harbin University of Commerce, Harbin 150076, \\ China
}

*Corresponding Author: hashangda117@163.com

\begin{abstract}
Three flavonoids compounds, 5,6,7,8,3',4'hexamethoxyflavone (1) 、5,6,7,8,4'-pentamethoxyflavon (2) 7,3 '- dihydroisofavones (3) were isolated from the Traditional Chinese medicine Cycas revojuta for the first time, and their structures were established on the basis of spectroscopic methods. The presences of these compounds (1-3) might be employed as the characteristic constituents of Cycas revojuta family.
\end{abstract}

Keywords: Cycas revojuta, flavonids, characteristic

constituents

\section{Introduction}

Cycas revojuta belongs to the family Cycas revojuta and was widely distributed in Guangxi province, Yunnan province, Sichuan province, Guizhou province, Hainan province and Taiwan province in China ${ }^{[1]}$. Previous phytochemical investigations resulted in the isolation of many compounds including biflavone, cycasin, amino acid, phenol glycosides, saccharide compounds, steroids, long chain compounds and pigment, etc ${ }^{[2-6]}$. In this study compounds (1-3) were isolated for the first time. The structures of these compounds were shown in Fig. 1.
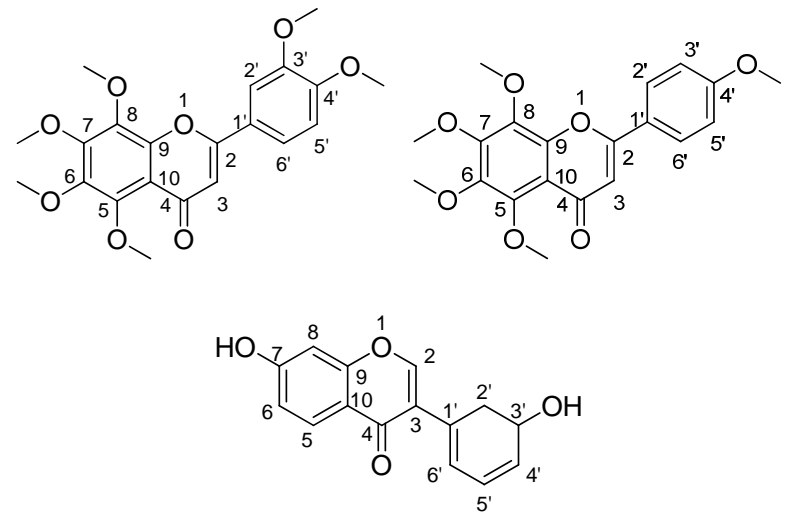

Fig. 1. Structure of compounds 1-3

\section{The Experiments And Materials}

\subsection{Separation And Extraction}

The air-dried leaves was exhaustively extracted with $95 \%$ ethanol after grounding into powder $(20.0 \mathrm{~kg})$. The solvent was removed under reduced pressure to afford an extract $(1.5 \mathrm{~kg})$. Then the extract was successively partitioned with petroleum ether, chloroform, ethyl acetate, and $n$-butanol. The chloroform extract (110 g) was subjected to a silica gel chromatography, eluting with a gradient of $\mathrm{CHCl}_{3} / \mathrm{MeOH}(100: 1-1: 1, \mathrm{v} / \mathrm{v})$, to give six fractions (A-F). Fraction C (9.6 g) was applied to silica gel column chromatography, eluting with $\mathrm{CHCl}_{3} / \mathrm{MeOH}(20: 1$ to $1: 1, \mathrm{v} / \mathrm{v}$ ), to furnish five fractions (1-5). Fraction 4 (5.3 g) was separated by a column of Sephadex LH-20 eluted with $\mathrm{CHCl}_{3} / \mathrm{MeOH} 100: 3,100: 7,100: 10$ and 100:20 to gave compounds 1 (3.2 mg) and 2 (16.6 mg). Compounds 3 (6.4 $\mathrm{mg}$ ) were obtained by recrystallization from $\mathrm{CHCl}_{3}$.

\subsection{Compounds Structural Analysis}

Compound 1 was obtained as yellow needles. Its molecular formula was determined as $\mathrm{C}_{22} \mathrm{H}_{21} \mathrm{O}_{8}$ by ESI-MS at $\mathrm{m} / \mathrm{z}$ 403.1315[M+H] $]^{+}$.The ${ }^{1} \mathrm{H}-\mathrm{NMR}$ and ${ }^{13} \mathrm{C}$-NMR spectra indicated six $\mathrm{sp}^{3}$ hybridization of high intensity of hydrogen proton signals; $\delta_{\mathrm{H}} 4.02(3 \mathrm{H}, \mathrm{s}) 、 3.96$ $(3 \mathrm{H}, \mathrm{s}) 、 3.88(3 \mathrm{H}, \mathrm{s}) 、 3.88(3 \mathrm{H}, \mathrm{s}) 、 3.85(3 \mathrm{H}, \mathrm{s})$ and 3.79 (3H, s), ${ }^{13} \mathrm{C}-\mathrm{NMR}$ (75 MHz, DMSO- d6) spectrum shown six carbon signals $\delta_{\mathrm{C}} 62.0 、 61.9 、 61.6 、 61.5 \times 2$ and 55.6, indicated the existence of 6 methoxy signals. $\delta_{\mathrm{H}} 7.65(1 \mathrm{H}$, d, $J=8.7 \mathrm{~Hz}) 、 7.55(1 \mathrm{H}, \mathrm{d}, J=1.8 \mathrm{~Hz})$ and $7.16(1 \mathrm{H}, \mathrm{d}, J=$ $1.8,8.7 \mathrm{~Hz}$ ) revealed the structure with a benzene ring with $\mathrm{ABX}$ coupling system, benzene ring of carbon signal corresponding to the $\delta_{\mathrm{C}} 127.9 、 114.8$ and 123.1.The ${ }^{13} \mathrm{C}-\mathrm{NMR}$ spectra given 21 carbon signals, remove 6 methoxyl matrix signal, the basic with the parent nucleus 15 carbon, speculated that the structure may be flavonoids compounds. $\delta_{\mathrm{H}} 6.72(1 \mathrm{H}, \mathrm{s})$ speculated that flavonoids three hydrogen proton signals. The above data, combined 
with the literature ${ }^{[7]}$, identification the compound as 5,6,7,8,3 ', 4 '-hexamethoxyflavone, the NMR spectrum data were shown in Fig. 2,3 and Table 1.

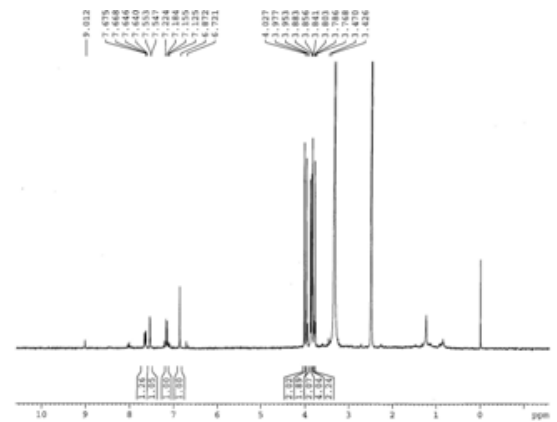

Fig. 2. The ${ }^{1} \mathrm{H}-\mathrm{NMR}$ spectrum of compound $\mathbf{1}$

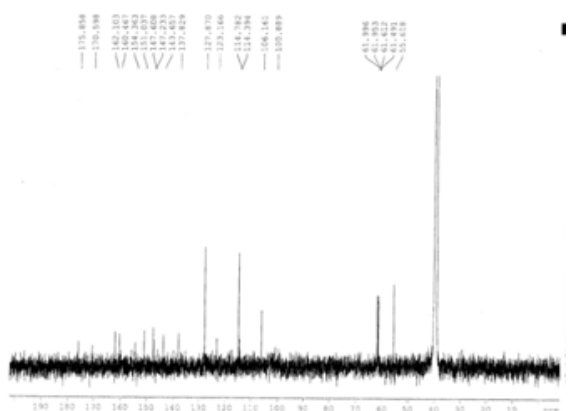

Fig. 3.The ${ }^{13} \mathrm{C}$-NMR spectrum of compound $\mathbf{1}$

Table 1. ${ }^{1} \mathrm{H}-\mathrm{NMR}(300 \mathrm{MHz})$ and ${ }^{13} \mathrm{C}-\mathrm{NMR}$ (75 MHz) spectral data of compound $\mathbf{1}$

\begin{tabular}{lcl}
\hline Positio & \multicolumn{1}{c}{$\delta_{\mathrm{C}}$} & \multicolumn{1}{c}{$\delta_{\mathrm{H}}(J$ in Hz$)$} \\
\hline 2 & 162.1 & - \\
3 & 106.1 & \multicolumn{1}{l}{$6.72(1 \mathrm{H}, \mathrm{s})$} \\
4 & 175.9 & - \\
5 & 147.6 & - \\
6 & 143.6 & - \\
7 & 151.0 & - \\
8 & 137.8 & - \\
9 & 147.2 & - \\
10 & 123.1 & - \\
1 & 162.1 & - \\
$2^{\prime}$ & 127.9 & $7.16(1 \mathrm{H}, \mathrm{dd}, J=2.7,8.7 \mathrm{~Hz})$ \\
3' & 160.5 & - \\
$4^{\prime}$ & 154.3 & - \\
5' & 114.8 & $7.55(1 \mathrm{H}, \mathrm{d}, J=1.8 \mathrm{~Hz})$ \\
6' & 127.9 & $7.65(1 \mathrm{H}, \mathrm{d}, J=8.7 \mathrm{~Hz})$ \\
\hline
\end{tabular}

Compound 2 was obtained as yellow needles. Its molecular formula was determined as $\mathrm{C}_{20} \mathrm{H}_{20} \mathrm{O}_{7}$ by ESI-MS at $\mathrm{m} / \mathrm{z}$ 374.1209[M+H] ${ }^{+}$. ${ }^{1} \mathrm{H}-\mathrm{NMR}(300 \mathrm{MHz}$, DMSO- d6) spectrum included five $\mathrm{sp}^{3}$ hydrogen proton signals at high intensity, $\delta_{\mathrm{H}} 4.02(3 \mathrm{H}, \mathrm{s}) 、 \delta_{\mathrm{H}} 4.02(3 \mathrm{H}, \mathrm{s}) \times 2$ 、 $3.85(3 \mathrm{H}, \mathrm{s})$ and $3.78(3 \mathrm{H}, \mathrm{s}) .{ }^{13} \mathrm{C}-\mathrm{NMR}(75 \mathrm{MHz}$, DMSOd6) given five carbon signals $\delta_{\mathrm{C}} 62.0 、 61.9 、 61.6 、 61.5$ and 55.8 , indicated the existence of 5 methoxy signals. $\delta_{\mathrm{H}} 8.0$ $(1 \mathrm{H}, \mathrm{d}, J=8.7 \mathrm{~Hz}) \times 2$ and $7.14(1 \mathrm{H}, \mathrm{d}, J=8.7 \mathrm{~Hz})$, suggested there is a counterpoint to replace benzene ring system, benzene ring of carbon signal corresponding to the $\delta_{\mathrm{C}} 123.2 、 119.4$ and $114.6 \times 2$. The ${ }^{13} \mathrm{C}-\mathrm{NMR}$ spectra given 20 carbon signals, remove 5 methoxyl matrix signal, the basic with the parent nucleus 15 carbon, speculated that the structure may be flavonoids compounds. $\delta_{\mathrm{H}} 6.77(1 \mathrm{H}, \mathrm{s})$ speculated tha position three hydrogen proton signals in flavonoids. The above data, combined with the literature ${ }^{[7]}$, identification the compound as 5,6,7,8,4'-pentamethoxyflavone, the NMR spectrum data were shown in shown in Fig. 4,5 and Table 2.

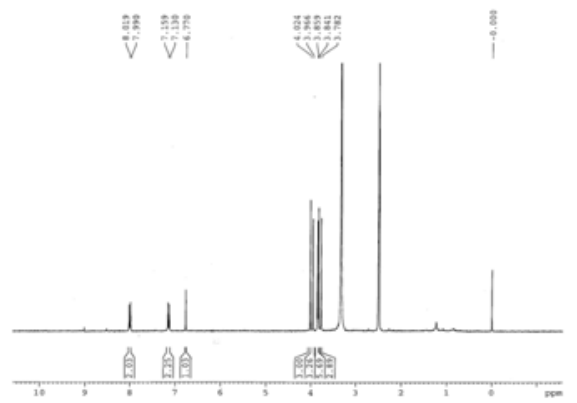

Fig.4. The ${ }^{1} \mathrm{H}-\mathrm{NMR}$ spectrum of compound 2

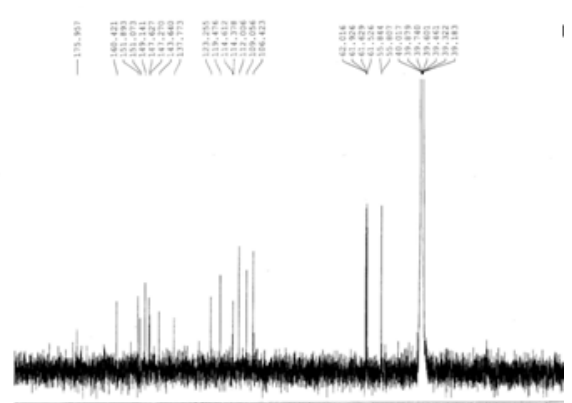

Fig. 5. The ${ }^{13} \mathrm{C}-\mathrm{NMR}$ spectrum of compound $\mathbf{2}$ 
Table 2. ${ }^{1} \mathrm{H}-\mathrm{NMR}(300 \mathrm{MHz})$ and ${ }^{13} \mathrm{C}-\mathrm{NMR}(75 \mathrm{MHz})$ spectral data of compound 2

\begin{tabular}{lrl}
\hline Positio & $\delta_{\mathrm{C}}$ & \multicolumn{1}{c}{$\delta_{\mathrm{H}}(J$ in Hz$)$} \\
\hline 2 & 160.4 & - \\
3 & 106.4 & $6.77(1 \mathrm{H}, \mathrm{s})$ \\
4 & 176.0 & \\
5 & 149.1 & - \\
6 & 137.7 & - \\
7 & 151.1 & - \\
8 & 143.6 & - \\
9 & 149.1 & - \\
10 & 112.0 & - \\
$1^{\prime}$ & 123.2 & - \\
$2^{\prime}$ & 123.2 & $8.01(1 \mathrm{H}, \mathrm{d}, J=8.7 \mathrm{~Hz})$ \\
3' & 114.6 & $7.14(1 \mathrm{H}, \mathrm{d}, J=8.7 \mathrm{~Hz})$ \\
$4^{\prime}$ & 151.8 & - \\
5' & 114.3 & $7.14(1 \mathrm{H}, \mathrm{d}, J=8.7 \mathrm{~Hz})$ \\
6' & 119.4 & $8.01(1 \mathrm{H}, \mathrm{d}, J=8.7 \mathrm{~Hz})$ \\
\hline
\end{tabular}

Compound 3 was obtained as colorless needles. Its molecular formula was determined as $\mathrm{C}_{15} \mathrm{H}_{12} \mathrm{O}_{4}$ by ESI-MS at $\mathrm{m} / \mathrm{z} \quad 257.0736[\mathrm{M}+\mathrm{H}]+{ }^{+} \mathrm{C}-\mathrm{NMR}(75 \mathrm{MHz}$, DMSO- $d_{6}$ ) given fiftteen carbon signals, speculated that the structure may be flavonoids compounds. $\delta_{\mathrm{H}} 8.74(1 \mathrm{H}, \mathrm{s})$ indicated the structure as isoflavone stem nucleus. $\delta_{\mathrm{H}} 8.30$ $(1 \mathrm{H}, \mathrm{d}, J=2.7 \mathrm{~Hz}) 、 8.10(1 \mathrm{H}, \mathrm{d}, J=9.0 \mathrm{~Hz})$ and $7.52(1 \mathrm{H}$, dd, $J=2.7,9.0 \mathrm{~Hz}$ ), revealed the structure with a benzene ring with $\mathrm{ABX}$ coupling system, benzene ring of carbon signal corresponding to the $\delta_{\mathrm{C}} 128.7 、 116.2$ and 112.6. The above data, combined with the literature ${ }^{[8]}$, identification the compound as 7,3'- $d$ ihydroisofavones, NMR spectrum data were shown in Fig. 6,7 and Table 3.

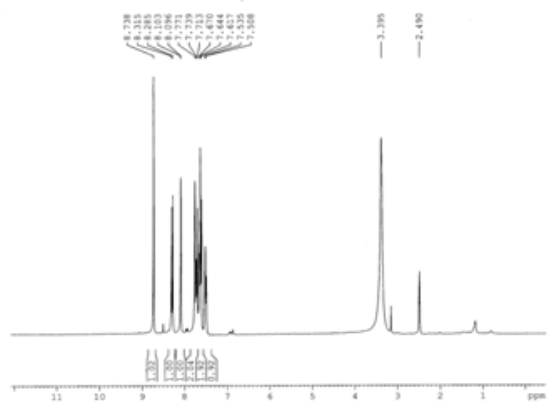

Fig.6. The ${ }^{1} \mathrm{H}-\mathrm{NMR}$ spectrum of compound 3

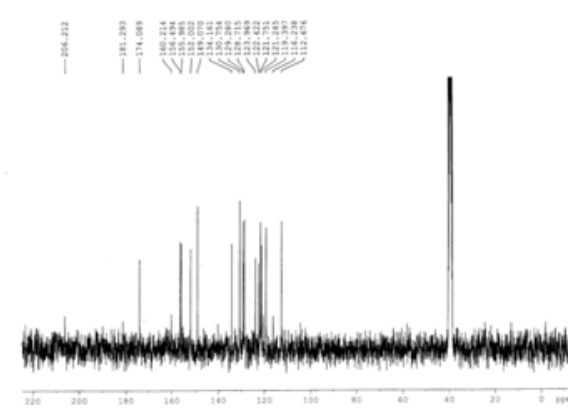

Fig. 7.The ${ }^{13} \mathrm{C}-\mathrm{NMR}$ spectrum of compound 3

Table 3. ${ }^{1} \mathrm{H}-\mathrm{NMR}(300 \mathrm{MHz})$ and ${ }^{13} \mathrm{C}-\mathrm{NMR}(75 \mathrm{MHz})$ spectral data

\begin{tabular}{crl}
\multicolumn{3}{c}{ of compound 3 } \\
\hline Positio & \multicolumn{1}{c}{$\delta_{\mathrm{C}}$} & \multicolumn{1}{c}{$\delta_{\mathrm{H}}(J$ in Hz$)$} \\
\hline 2 & 156.0 & $8.74(1 \mathrm{H}, \mathrm{s})$ \\
3 & 124.0 & - \\
4 & 174.0 & - \\
5 & 128.7 & $8.30(1 \mathrm{H}, \mathrm{d}, J=2.7 \mathrm{~Hz})$ \\
6 & 116.2 & $8.010(1 \mathrm{H}, \mathrm{d}, J=9.0 \mathrm{~Hz})$ \\
7 & 160.2 & - \\
8 & 112.6 & $7.52(1 \mathrm{H}, \mathrm{dd}, J=2.7,9.0 \mathrm{~Hz})$ \\
9 & 152.0 & - \\
10 & 119.3 & - \\
1 & 130.1 & - \\
2' & 119.3 & $7.78(1 \mathrm{H}, \mathrm{s})$ \\
3' & 156.4 & - \\
4' & 134.1 & $7.72(1 \mathrm{H}, \mathrm{m})$ \\
5' & 129.9 & $7.65(1 \mathrm{H}, \mathrm{m})$ \\
\hline
\end{tabular}

\section{Copyright}

Papers submitted to ICISIP must describe original and unpublished researches. They should not have been submitted to other conferences or journals. Any paper which is under review elsewhere will not be considered for publication. Once an eligible paper is accepted, it will be published under a Creative Commons Attribution 3.0 (CC BY 3.0) License.

\section{Conclusions}

The Cycas revojuta was an important genus in Cycas revojuta family, which has approximately 70 species in China. Three flavonoids compounds, 5,6,7,8,3',4'hexamethoxyflavone (1) 、5,6,7,8,4'-pentamethoxyflavon (2)、7,3'- dihydroisofavones (3) were isolated from the fruits of Cycas revojuta for the first time, and their structures were established on the basis of spectroscopic 
methods. Compounds 1-3 were isolated for the first time form the family Cycas revojuta, whose appears rich the compounds diversity to family Cycas revojuta.

\section{Acknowledgment}

This study was supported by Science and technology research project of Heilongjiang province department of education (NO. 12541208).Thanks were due to Mrs. Li Wen and Mr. Yi Sha for the measurements of NMR spectra. In addition, the authors are grateful to Professor Xiao-Qiu Liu and Qi-Shi Sun for their kind help in the collection and the identification of the plant samples.

\section{References}

(1) James A Ingham, PauII. Forster and Michael D.Crisp : "Ancient relicts or recent dispersal: how long have cycads been in central Australia”, Diversity and Distributions, Vol. 19, No.3, pp. 307-316, 2013

(2) Tapan Kumar Mohanta, Andrea Occipinti and Simon Atsbaha Zebelo : "Ginkgo biloba responds to herbivory by activating early signaling and direct defenses", PLoS One , Vol. 7, No.3, pp. e32822, 2012

(3) Tomokazu Haraguchi, Keiichi Nomura and Fumio yagi : "Cloning and expression of a mannose-binding jacalin-related lectin from leaves of Japanese cycad (Cycas revoluta Thunb.)", Bioscience, biotechnology, and biochemistry, Vol. 70, No.9, pp. 2222-2229, 2006

(4) Donald G Barceloux : "Cycad seeds and chronic neurologic disease (Cycas species)", Medical Toxicology of Natural Substances: Foods, Fungi, Medicinal Herbs, Plants, and Venomous Animals, pp. 54-58, 2009

(5) Thomas Krüger, Bettina Möncha and Steven Oppenhäusera : "LC-MS/MS determination of the isomeric neurotoxins BMAA methylamino-l-alanine) and DAB (2, 4-diaminobutyric acid) in cyanobacteria and seeds of Cycas revoluta and Lathyrus latifolius", Toxicon, Vol. 55, No.2, pp. 547-557, 2010

(6) Moawad A, Hetta M, Zjawiony J K : "Phytochemical investigation of Cycas circinalis and Cycas revoluta leaflets: moderately active antibacterial biflavonoids", Planta medica, Vol.76, No.8, pp. 796-802, 2010

(7) Saem Han, Hye Min Kim and Jeong Min Lee : "Isolation and identification of polymethoxyflavones from the hybrid Citrus, hallabong”, Journal of agricultural and food chemistry, Vol.58, No.17, pp.
9488-9491, 2010

(8) Terezinha de J. Faria, Luiz G. Fonseca e Silva and José D. de Souza Filho : "Synthesis and trypanocidal activity of 7, 2'-dioxygenated isoflavones and oxypropanolamine derivatives", Journal of the Brazilian Chemical Society, Vol.16, No.16B, pp. 1415-1419, 2005 